\title{
On-road and \\ Dynamometer Evaluation of Vehicle Auxiliary Loads
}

\section{SAE World Congress}

\author{
Barney Carlson
}

(Idaho National Laboratory)

Kevin Stutenberg

(Argonne National Laboratory)

U.S. Department of Energy

National Laboratory

operated by

Battelle Energy Alliance

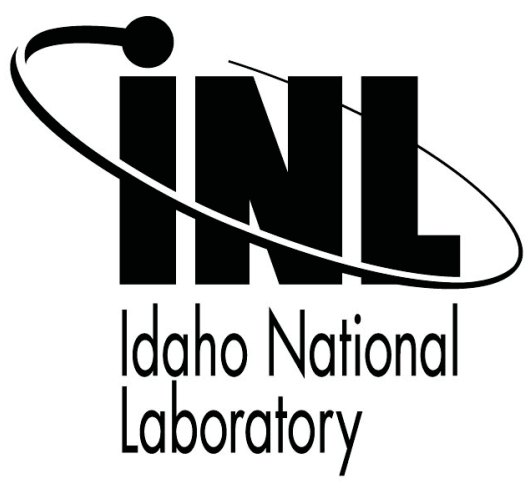

October 2015

This is a preprint of a paper intended for publication in a journal or proceedings. Since changes may be made before publication, this preprint should not be cited or reproduced without permission of the author. This document was prepared as an account of work sponsored by an agency of the United States Government. Neither the United States Government nor any agency thereof, or any of their employees, makes any warranty, expressed or implied, or assumes any legal liability or responsibility for any third party's use, or the results of such use, of any information, apparatus, product or process disclosed in this report, or represents that its use by such third party would not infringe privately owned rights. The views expressed in this paper are not necessarily those of the United States Government or the sponsoring agency. 



\title{
On-Road and Dynamometer Evaluation of Vehicle Auxiliary Loads
}

\author{
Richard "Barney" Carlson, Idaho National Laboratory \\ Jeffrey Wishart, Intertek Testing Services NA Inc. \\ Kevin Stutenberg, Argonne National Laboratory
}

\begin{abstract}
Laboratory and on-road vehicle evaluation is conducted on four vehicle models to evaluate and characterize the impacts to fuel economy of real-world auxiliary loads.

The four vehicle models in this study include the Volkswagen Jetta TDI, Mazda 3 i-ELOOP, Chevrolet Cruze Diesel, and Honda Civic GX (CNG). Four vehicles of each model are included in this; sixteen vehicles in total. Evaluation was conducted using a chassis dynamometer over standard drive cycles as well as twelve months of on-road driving across a wide range of road and environmental conditions.
\end{abstract}

The information gathered in the study serves as a baseline to quantify future improvements in auxiliary load reduction technology. The results from this study directly support automotive manufacturers in regards to potential "off-cycle" fuel economy credits as part of the Corporate Average Fuel Economy (CAFE) regulations, in which credit is provided for advanced technologies in which reduction of energy consumption from vehicle auxiliary loads can be demonstrated.

The observed on-road auxiliary load varied from $135 \mathrm{~W}$ to over 1200 $\mathrm{W}$ across a wide range of ambient conditions and utilization patterns. The annual average auxiliary load varied across vehicle models from $310 \mathrm{~W}$ to $640 \mathrm{~W}$. Ambient temperature was the most predominant factor to impact auxiliary load since air conditioner (A/C) operation is prevalent at high ambient temperature and heating system operation is prevalent at cold ambient temperatures. Additionally the impact of auxiliary load on vehicle fuel economy was determined to be typically between $7.5 \%$ and $18 \%$ of the fuel consumed during onroad operation of the four vehicle models in this study.

During dynamometer testing, auxiliary loads were captured from several key locations along the low-voltage bus, including the alternator output, the low-voltage battery, and select other locations dependent upon the vehicle configuration. Dynamometer testing was then conducted on both certification and custom constant-speed drive cycles at three ambient temperatures $\left(-7^{\circ} \mathrm{C}, 23{ }^{\circ} \mathrm{C}\right.$, as well as $35^{\circ} \mathrm{C}$ with $850 \mathrm{~W} / \mathrm{m}^{2}$ of solar emulation). This instrumentation and test methodology provides an accurate understanding of the energy use by the accessory system from these four vehicle technologies.

This paper details and discusses the dynamometer and on-road evaluation results of the auxiliary load from the sixteen vehicles over the twelve month period.

\section{Introduction}

As part of the testing and data collection support to the U.S. Department of Energy's (DOE) Advanced Vehicle Testing Activity (AVTA) [1], Idaho National Laboratory, Argonne National Laboratory, and Intertek Center for Evaluation of Clean Energy Technology (CECET) test advanced technology vehicles in on-road fleets, on test tracks, and in laboratory settings in order to determine the real-world petroleum consumption reduction potential of various advanced vehicle technologies. One strategy for petroleum consumption reduction is to reduce the auxiliary, $12 \mathrm{~V}$ loads of the vehicle. This strategy has been explored in recent research [2-5] and several U.S. automotive manufacturers are also interested in developing novel methods for improved fuel economy.

Vehicle auxiliary load data collection, analysis, and characterization were conducted on sixteen non-electrified vehicles as part of the AVTA on-road vehicle evaluation. This auxiliary load characterization study directly supports automotive manufacturers in regards to potential "off-cycle" fuel economy credits that are part of the U.S. CAFE regulations, in which credit is provided for advanced technologies that reduce the energy consumption from vehicle auxiliary loads. A few examples of these advanced technologies are advanced alternators, HVAC systems, active aerodynamics systems (such as movable grille shutters that close at high speeds), and lighting systems. The data collection and analysis details the auxiliary load data collected during the on-road operation of 126,000 miles of 16 non-electrified vehicles (four Volkswagen Jetta TDI, four Mazda 3 i-ELOOP, four Chevrolet Cruze Diesel, and four Honda Civic GX (CNG) vehicles).

Chassis dynamometer testing was conducted on the same four vehicle models noted above, over several standard drive cycles (e.g., UDDS, HWFET, and US06) at three separate temperatures of $-7{ }^{\circ} \mathrm{C}, 23^{\circ} \mathrm{C}$, as well as $35^{\circ} \mathrm{C}$ with $850 \mathrm{~W} / \mathrm{m}^{2}$ of solar emulation. Instrumentation was installed on each vehicle prior to dynamometer evaluation in order to capture $12 \mathrm{~V}$ power flow and energy consumption by the vehicle accessories. This was used to correlate and cross reference the on-road data collection across varying ambient conditions and temperatures.

\section{Vehicle Models Evaluated}

The sixteen vehicles in this study include four 2013 Volkswagen Jetta TDI, four 2012 Honda Civic CNG, four 2014 Mazda 3 i-ELOOP, and four 2014 Chevrolet Cruze Diesel vehicles. The vehicles are operated on-road in document delivery courier fleets and taxi fleets in Arizona, Texas, and Oklahoma. Routine maintenance is performed on the vehicles per the manufacturer's maintenance schedule. 
The test vehicles selected for the project were diesel vehicles (Jetta TDI and Cruze Diesel), natural gas vehicles ((NGVs) Civic CNG), and an advanced conventional vehicle (3 i-ELOOP). The vehicles were chosen because of automotive OEM requests to study nonelectrified vehicles auxiliary load characteristics during on-road operation. The ultra-capacitor of the Mazda 3 i-ELOOP helps reduce demand on the $12 \mathrm{~V}$ battery, but the vehicle architecture was deemed sufficiently conventional to be included in the study. Furthermore, each vehicle model has unique features which are of interest and are shown in Table 1. The Jetta TDI and Chevy Cruze Diesel both utilize a four-cylinder, turbo diesel engine. The Jetta TDI has a six-speed, dual-clutch transmission, whereas the Cruze Diesel has a conventional six-speed, automatic transmission. The Honda Civic CNG utilizes compressed natural gas $(\mathrm{CNG})$ as the sole fuel source. Of importance, the Civic CNG does not use a fuel pump, which is important with respect to auxiliary load. The Mazda 3 i-ELOOP utilizes a direct-injection, gasoline engine and a six-speed transmission. Additionally, the Mazda 3 i-ELOOP uses a $25 \mathrm{~V}$ capacitor and power electronics to supplement and aid the alternator system in providing electrical power to the auxiliary loads to improve operating efficiency.

Table 1. Test vehicle descriptions

\begin{tabular}{|l|l|}
\hline Vehicle Model & $\begin{array}{l}\text { Notable Characteristics and } \\
\text { Features }\end{array}$ \\
\hline 2013 VW Jetta TDI & $\begin{array}{l}\text { Turbo diesel engine with dual } \\
\text { clutch transmission }\end{array}$ \\
\hline 2014 Chevrolet Cruze Diesel & $\begin{array}{l}\text { Turbo diesel engine with } \\
\text { automatic transmission }\end{array}$ \\
\hline 2012 Honda Civic CNG & $\begin{array}{l}\text { CNG naturally aspirated engine } \\
\text { with automatic transmission }\end{array}$ \\
\hline 2014 Mazda 3 i-ELOOP & $\begin{array}{l}\text { 25 V capacitor and power } \\
\text { electronics system to aid } \\
\text { alternator efficiency performance }\end{array}$ \\
\hline
\end{tabular}

\section{Testing Overview}

The sixteen vehicles (four of each vehicle model) were instrumented with current and voltage sensors as well as controller area network (CAN) message monitoring equipment. On-board data acquisition (DAQ) systems from Isaac Instruments were installed in the vehicles to record the current, voltage, and CAN messages. This information was used to determine the vehicle operating conditions, utilization patterns and the auxiliary loads during those conditions.

Prior to testing, all features of the tests vehicles which can apply a substantial load to the $12 \mathrm{~V}$ system were identified. For each feature identified, the amperage rating for the fuse through which power flows to that feature's hardware was also documented. The vehicle state (i.e., key on, engine off/key on, engine on) during which each feature becomes functional was also determined.

In order to conduct the characterization of the loads on the $12 \mathrm{~V}$ system, the vehicle was instrumented using current sensors on the cables leading to the various feature hardware. The current sensors were connected to the Isaac Instruments DAQ systems, and the data were set to capture at a $1 \mathrm{~Hz}$ rate. The current sensor data were also corroborated using signals that were deciphered from the vehicle CAN system.

The $12 \mathrm{~V}$ power draws were separated into two categories: (1) power draws during engine off, and (2) power draws during engine on. There was some overlap between the two groups, with some power draws occurring in both cases, while other power draws occurring only with the engine on because the engine power is required. The power draws that were measured are shown in Table 2 (power draw occurring only with the engine on are indicated by blue shading).

Table 2. Tested individual power draws

\begin{tabular}{|l|l|}
\hline Parking lights & Cabin fan (at all available speeds) \\
\hline Dashboard lights & Radio (at high volume) \\
\hline $\begin{array}{l}\text { Headlights (low and high } \\
\text { beam) }\end{array}$ & $\begin{array}{l}\text { Windshield wipers (low and high } \\
\text { speed) }\end{array}$ \\
\hline Dome lights & Windshield washer (front and rear) \\
\hline $\begin{array}{l}\text { Moon roof (open and } \\
\text { close) }\end{array}$ & Driver's window \\
\hline Taxi light and meter* & DAQ power draw \\
\hline $\begin{array}{l}\text { Driver and passenger seat } \\
\text { heaters }\end{array}$ & $\begin{array}{l}\text { Air conditioning (ECO, Normal, } \\
\text { and MAX, with varying fan speeds) }\end{array}$ \\
\hline Front and Rear defrosters & Electric power steering \\
\hline Brake lights & Reverse lights \\
\hline
\end{tabular}

* Some of the test vehicles are in taxi fleets

The test vehicles were deployed into AVTA project partner fleets in several locations:

- $\quad$ Phoenix, AZ: VW Jetta TDI

- Dallas and Houston, TX: Chevrolet Cruze Diesel

- Oklahoma City, OK: Honda Civic CNG

- Phoenix, AZ: Mazda 3 i-ELOOP

The vehicles operate within these fleets in the same manner as other vehicles within the same fleet, except that the drivers maintain a log of all refueling, and all maintenance is recorded.

The fleets are couriers that accumulate up to 500 miles per day, and this rapid accumulation helps provide a large amount of on-road operation data in a condensed period of time. The vehicles are driven by multiple drivers to avoid driver bias, and the vehicles are driven in a wide variety of drive cycles, from intra-city to urban to highway to interstate roads, with topographical variation, although there is no pre-determined driving pattern that is forced upon the fleets. Further, the vehicles are driven year-round, with results in significant temperature variation.

The Isaac DAQ systems capture the on-road operation data, and the base of operations for each fleet is equipped with Wi-Fi routers that allow for automatic data upload whenever the vehicle is in the vicinity. In this way, the $12 \mathrm{~V}$ load characterization data were uploaded on a nearly a daily basis to ensure data continuity and data completeness.

\section{Individual Load Benchmark Evaluation}

A specific auxiliary load test was completed on each vehicle model to measure the load of individual accessories and components. Additionally, the base auxiliary load of the vehicle was measured with all driver controlled accessories in the off position with the engine off and with the engine idling. Figure 1 shows the measured values for the individual auxiliary loads. Note the Honda Civic CNG is not equipped with seat heaters, rear defroster, or electric power steering. 


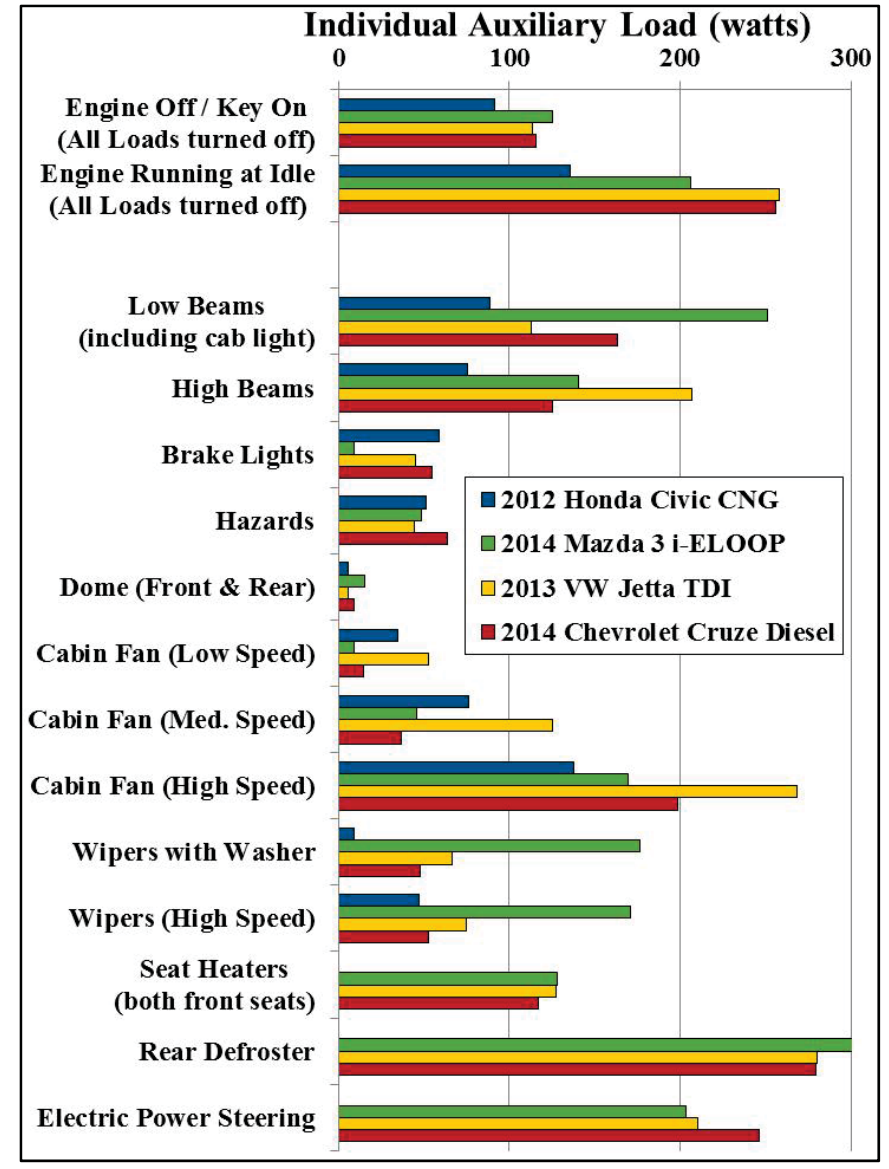

Figure 1. Individual auxiliary load characterization

Table 3 shows the minimum auxiliary load when the engine is idling and all driver controlled accessories are in the off position. Note the wide range of auxiliary load across the vehicle models. The Honda Civic CNG has the lowest auxiliary load of the four vehicle models in part due to not having a fuel pump. Also of note, the two vehicles with turbo diesel powertrains have quite similar auxiliary loads at idle $(256 \mathrm{~W}$ and $258 \mathrm{~W})$ when all accessories are turned off.

Table 3. Minimum auxiliary load with Engine idling (all accessories off)

\begin{tabular}{|l|c|}
\hline Vehicle Model & $\begin{array}{l}\text { Steady State Auxiliary Load } \\
\text { with Engine Idling and All } \\
\text { Accessories Off (W) }\end{array}$ \\
\hline 2013 VW Jetta TDI & 258 \\
\hline 2014 Chevy Cruze Diesel & 256 \\
\hline 2012 Honda Civic CNG & 136 \\
\hline 2014 Mazda 3 i-ELOOP & 206 \\
\hline
\end{tabular}

\section{Chassis Dynamometer Testing}

Three of the vehicles were also tested on a chassis dynamometer in order to provide a thorough evaluation while under controlled, repeatable conditions within a temperature controlled environmental chamber. The standard U.S. certification drive cycles were run, as well as customized drive cycles to capture the steady-state vehicle accessory load. This testing was conducted at Argonne National Lab's Advanced Powertrain Research Facility as shown in Figure 2.

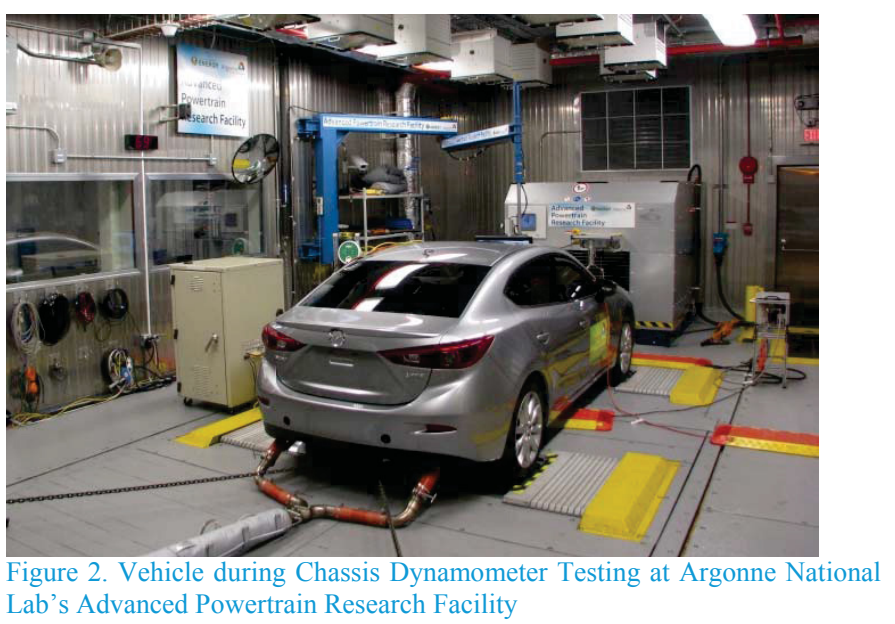

Certification drive cycles were utilized in order to provide a base for the variation in accessory loads that can be compared and contrasted with the variation seen in the on-road test results. These certification cycles included the UDDS, HWFET, US06, and SC03, with all but the SC03 cycle performed at the test cell temperatures of $-7^{\circ} \mathrm{C}, 23$ ${ }^{\circ} \mathrm{C}$, as well as $35^{\circ} \mathrm{C}$ with solar emulation of $850 \mathrm{~W} / \mathrm{m}^{2}$.

Instrumentation of each vehicle, which focused on accessory load measurements, included a voltage tap across the vehicles $12 \mathrm{~V}$ battery, a current clamp on the cable providing vehicle power from the alternator, and a separate current clamp on the negative side of the $12 \mathrm{~V}$ battery. Power at each location was calculated using a Hioki 3390 power analyzer, and logged at a frequency of $10 \mathrm{~Hz}$. Accessory load average power was determined by subtracting the energy delivered to the $12 \mathrm{~V}$ battery from energy supplied by the alternator, and divided the result by the time duration of the cycle.

Vehicle accessories remained in the standard conditions when the vehicle was operated on the dynamometer cycles. This included the HVAC system turned off at the test temperature of $23{ }^{\circ} \mathrm{C}$, and set to an automatic setting of $22{ }^{\circ} \mathrm{C}$ when at the test temperatures of $-7^{\circ} \mathrm{C}$ and $35{ }^{\circ} \mathrm{C}$. The vehicle radio remained off during all tests, and all lights were left at the settings in which the vehicle defaulted to upon the "key on" state.

The average power required for each vehicle model over the standard drive cycles can be seen in Figure 3 including cold start (CS) and hot start (HS) drive cycles.

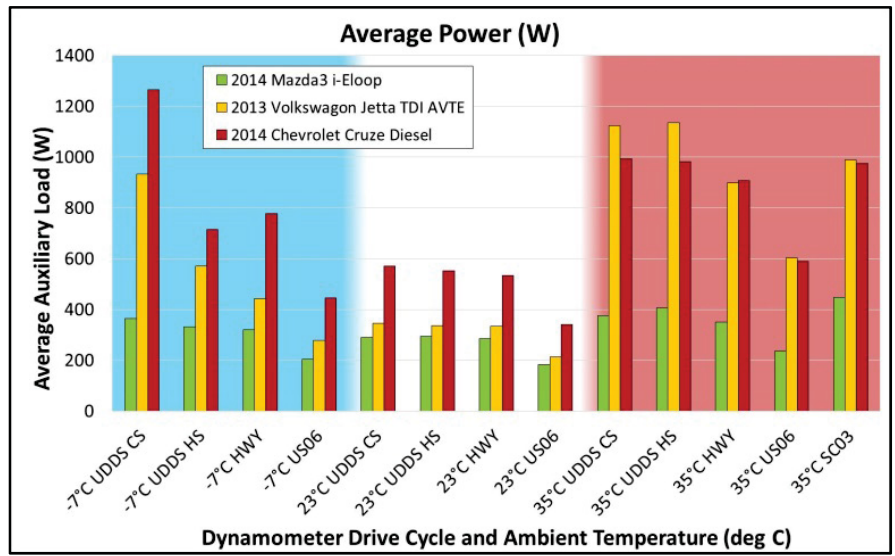

Figure 3. Average auxiliary load power over the standard drive cycles at varying temperatures 
Calculation of the vehicle energy consumption over the standard drive cycles is another metric that allows for a direct comparison with energy useage during on-road operation. The results of this comparison are shown in Figure 4.

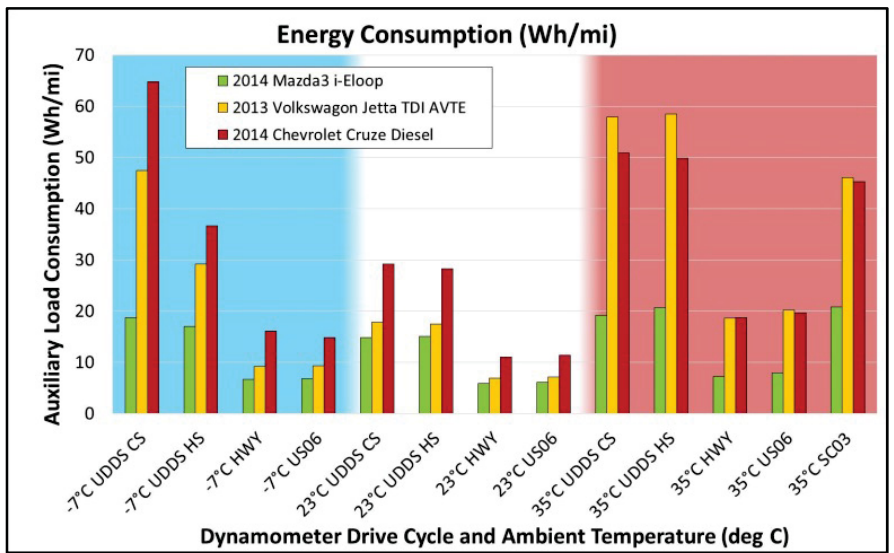

Figure 4. Energy consumption over the standard drive cycles at varying temperatures

In order to capture the vehicles' steady-state energy consumption, at $22{ }^{\circ} \mathrm{C}$ and at a constant speed, a custom cycle was developed for vehicle operation on the dynamometer. This drive cycle consisted of vehicle preconditioning to operating temperature with a $55 \mathrm{mph}$ steady-state speed, followed by the drive cycle in which the vehicle speed was increased, in increments of $10 \mathrm{mph}$, from $10 \mathrm{mph}$ to 80 $\mathrm{mph}$, and then reduced, again in increments of $10 \mathrm{mph}$, from $80 \mathrm{mph}$ to $10 \mathrm{mph}$. Each speed was held for 30 seconds duration. During each steady-state speed, auxiliary load was measured for each vehicle model. The results from this steady state dynamometer testing are shown in Figure 5.

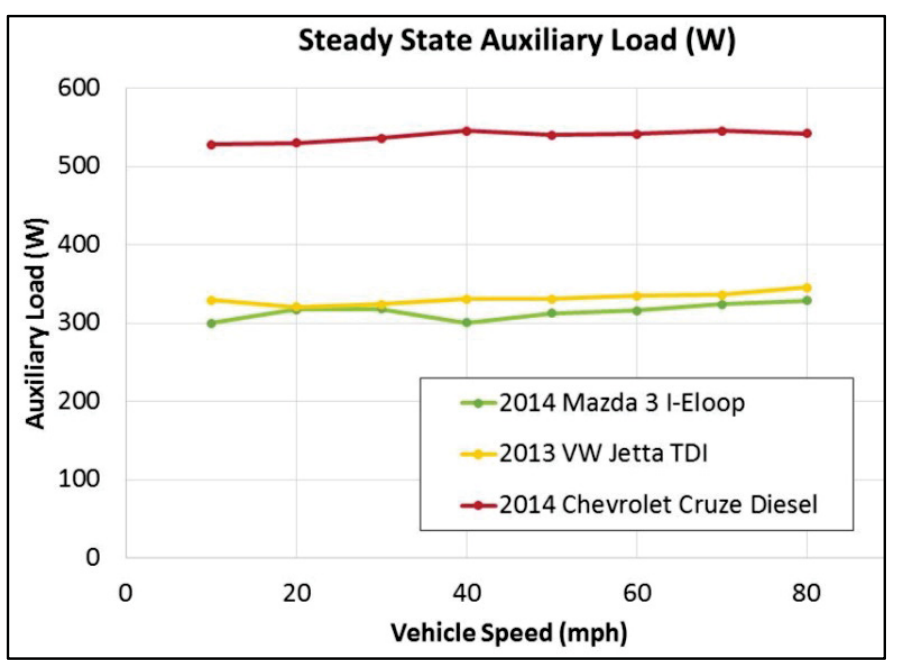

Figure 5. Auxiliary load measured at steady state speeds

After accounting for slight variations due to battery charging, the average accessory load of each of the three test vehicles was found to remain within $15 \mathrm{~W}$ from the mean value through the duration of the steady-state speeds. Additionally, these values fall in line with the average values seen on the $23{ }^{\circ} \mathrm{C}$ drive cycles, thought slight offsets were seen to occur due to varying vehicle operational requirements such as cooling fan loading, and other powertrain-related systems.

Through the duration of dynamometer testing on the three vehicle models, accessory load remained consistent with the results from the standard drive cycles. Meanwhile, it can be seen in Figure 3 and
Figure 4 that variations in ambient temperature result in a wide ranging addition of accessory loads. This was further quantified with the collection of on-road data from the same vehicle models.

\section{On-Road Data Collection and Analysis}

Over a twelve month period, September 2014 through August 2015, data was recorded and analyzed from the sixteen vehicles while operating in the on-road fleet. The auxiliary load was measured from the $12 \mathrm{~V}$ system of each vehicle and energy consumption was calculated. Table 4 shows that the annual average auxiliary load for each vehicle model varies from $310 \mathrm{~W}$ to $640 \mathrm{~W}$ across the vehicle models. This variation is due to differences in accessory power consumption variation between the four vehicle models as well as driver variability in accessory utilization.

Table 4. Fleet average on-road auxiliary load per vehicle model

\begin{tabular}{|l|c|}
\hline \multicolumn{1}{|c|}{ Vehicle Model } & Average Auxiliary Load (W) \\
\hline 2013 VW Jetta TDI & 639.7 \\
\hline 2014 Chevy Cruze Diesel & 561.2 \\
\hline 2012 Honda Civic CNG & 309.8 \\
\hline 2014 Mazda 3 i-ELOOP & 425.0 \\
\hline
\end{tabular}

The average auxiliary load on a quarterly basis is determined and shown in Figure 6. The auxiliary load varies across the four seasons and is significantly different between the vehicle models. All of the vehicle models showed the highest auxiliary load during the summer months primarily due to increased air conditioning usage. In contrast, the lowest auxiliary load was the lowest during the winter months for only two of the four models (Jetta TDI and Civic CNG). The other two models did not have minimum auxiliary loads during winter months likely due to increased defroster operation, heated seats, and other cold weather accessories.

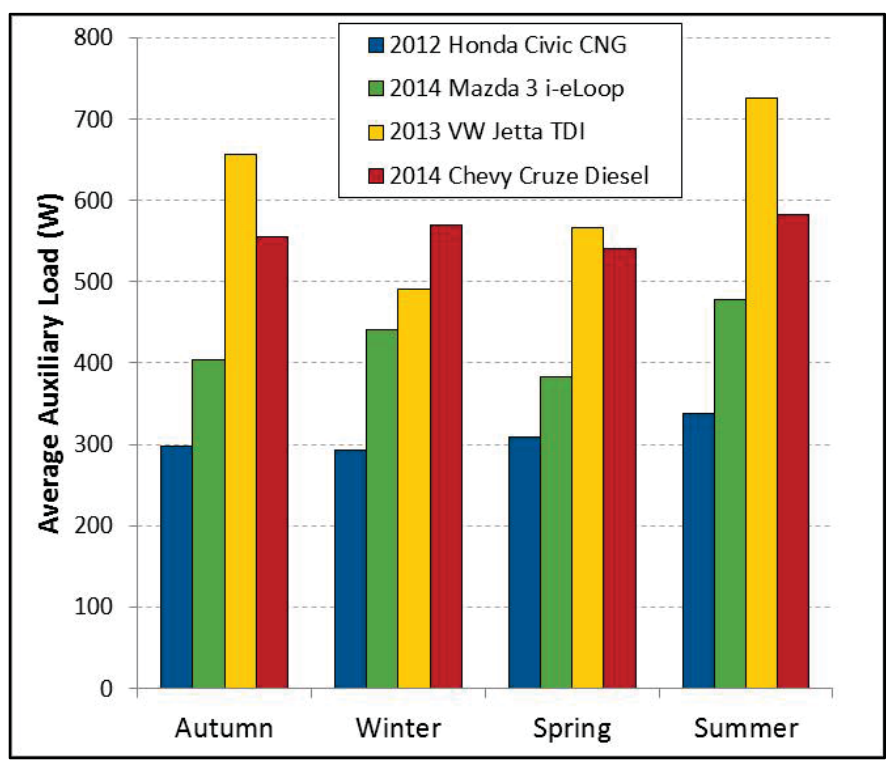

Figure 6. Seasonal variation of average on-road auxiliary load by vehicle model

On-road operation resulted in a wide range of auxiliary load power that varied in measurement from $135 \mathrm{~W}$ to over $1200 \mathrm{~W}$. Figure 7 shows a histogram of the auxiliary load from each vehicle over the one year on-road data collection period. The results shown are the average auxiliary load for each driving trip which is defined as a keyon to key-off event in which a minimum distance of 0.5 miles was 
traveled. There is notable similarity amongst the four vehicles of each model, but the results are not identical, likely due to natural variability in driver choice of accessory operation, ambient temperature, driving patterns, and many other factors (as opposed to difference in power consumption of auxiliary loads within a vehicle model).

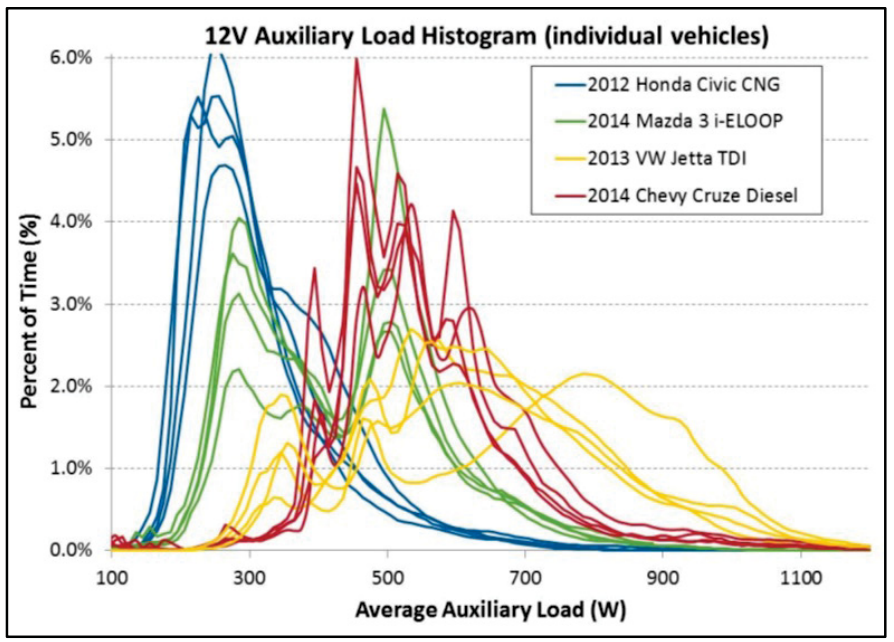

Figure 7. Histogram of on-road auxiliary load of each vehicle

Figure 8 shows the vehicle model average of the results displayed in Figure 7 . This more clearly shows the auxiliary load differences between vehicle models including single and multi-modal distributions. The Honda Civic CNG shows a single mode distribution with a mode of $250 \mathrm{~W}$. In contrast, the other vehicles show a multiple mode distribution. The Mazda 3 i-ELOOP for instance has two modes, one near $285 \mathrm{~W}$ and the other near $500 \mathrm{~W}$. This variation reinforces the wide range of accessory operation as determined by the driver preferences.

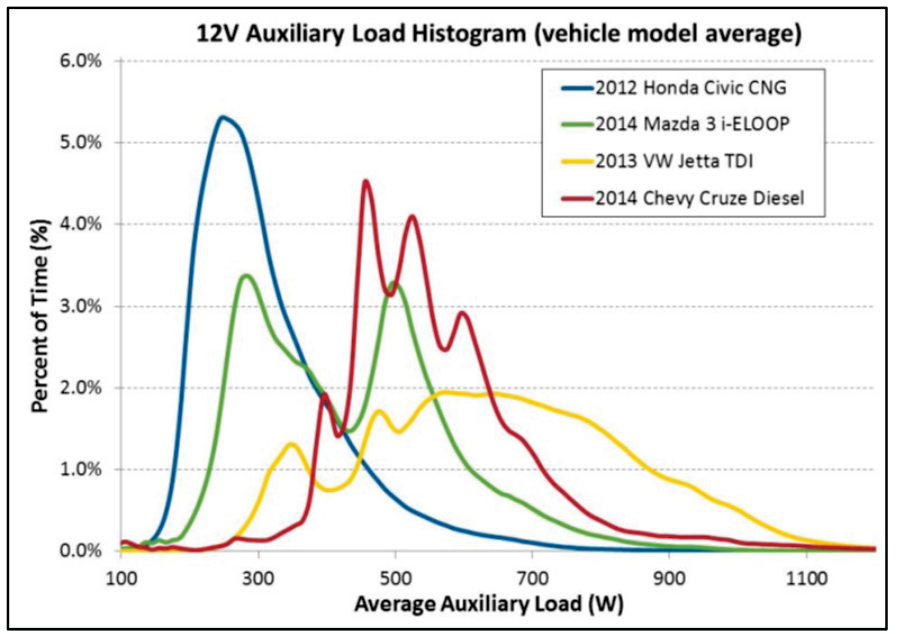

Figure 8. Histogram of on-road vehicle model averaged auxiliary load

Analysis of the on-road data showed that ambient temperature was the single largest factor to impact auxiliary load during the twelve month on-road evaluation. Figure 9 shows the auxiliary load of the four vehicle models across a wide range of ambient temperature from the on-road data collection. As expected the auxiliary load is at a minimum between $15{ }^{\circ} \mathrm{C}$ and $30{ }^{\circ} \mathrm{C}$. At colder and hotter temperatures the auxiliary load increased due to increased use of climate control, defroster, heat seats and other accessories. All four vehicle models utilize air conditioner $(\mathrm{A} / \mathrm{C})$ compressors that are belt driven from the engine accessory drive belt. This means the power required by the compressor for the working fluid is not included in the auxiliary loads as measured in this study. However, during A/C operation there are several electrical loads operating including the interior cabin fan, the condenser fan, and the electrically operated clutch on the $\mathrm{A} / \mathrm{C}$ compressor. These auxiliary loads are included in the measurements of this study and will increase as compressor and condenser fan cycles at a greater rate at higher temperatures and when the driver operates the interior fan at a higher fan speed.

For the Jetta TDI this impact of ambient temperature on auxiliary load doubled the auxiliary load from $470 \mathrm{~W}$ at $20^{\circ} \mathrm{C}$ to $956 \mathrm{~W}$ at 45 ${ }^{\circ} \mathrm{C}$. Other vehicle models showed lesser impact on auxiliary load due to ambient temperature. For instance the Honda Civic CNG showed a variation from $290 \mathrm{~W}$ to $360 \mathrm{~W}$ across the range of temperature encounter during the year of driving. This smaller impact by ambient temperature as compared to the other vehicle models may partially be explained by the fact that these four Honda Civic CNG vehicles were not equipped with heated seats, rear defroster or other accessories that are typically used at cold temperatures.

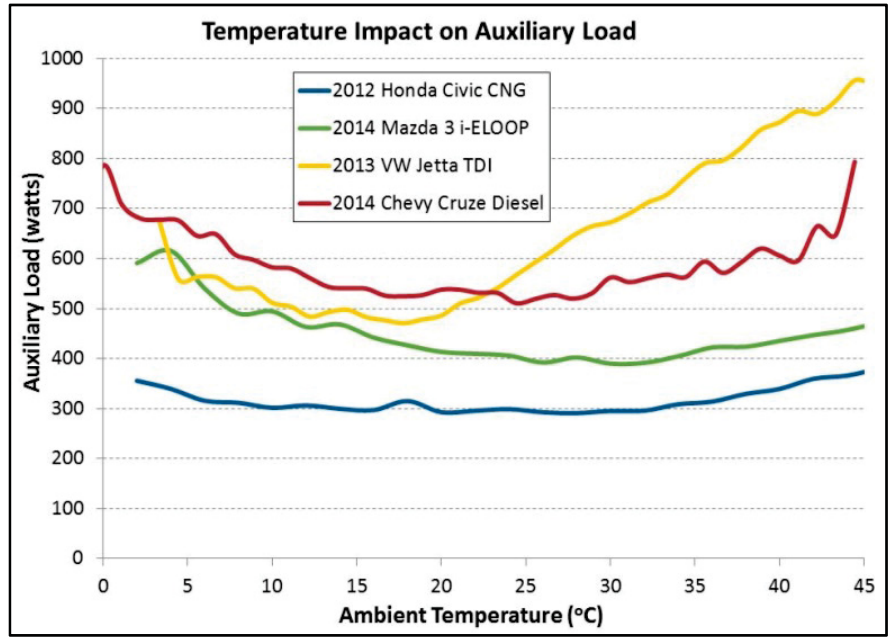

Figure 9. Impact of ambient temperature on auxiliary load

To determine overall impact to vehicle energy consumption, the auxiliary load energy consumption was calculated from the on-road data. This is determined from the same on-road data as shown in Figures 7 through 9, but it is determined as an energy per distance basis. Figure 10 shows the energy consumption results from the four vehicle models. It is observed that the overall trend of auxiliary load energy consumption is the same as auxiliary load power when comparing Figure 9 to Figure 10. In Figure 10 however, more variability in the results can be seen. This is again due to variation is driving patterns such as city versus highway driving, amount of idle time, trip distance, and many other factors. Figure 10 shows that the nominal auxiliary load energy consumption is between 10 and 35 $\mathrm{Wh} / \mathrm{mi}$ across the four vehicle models. Also, as seen previously from auxiliary load power, the auxiliary load energy consumption doubles at high temperatures for the VW Jetta TDI up to $70 \mathrm{Wh} / \mathrm{mi}$. 


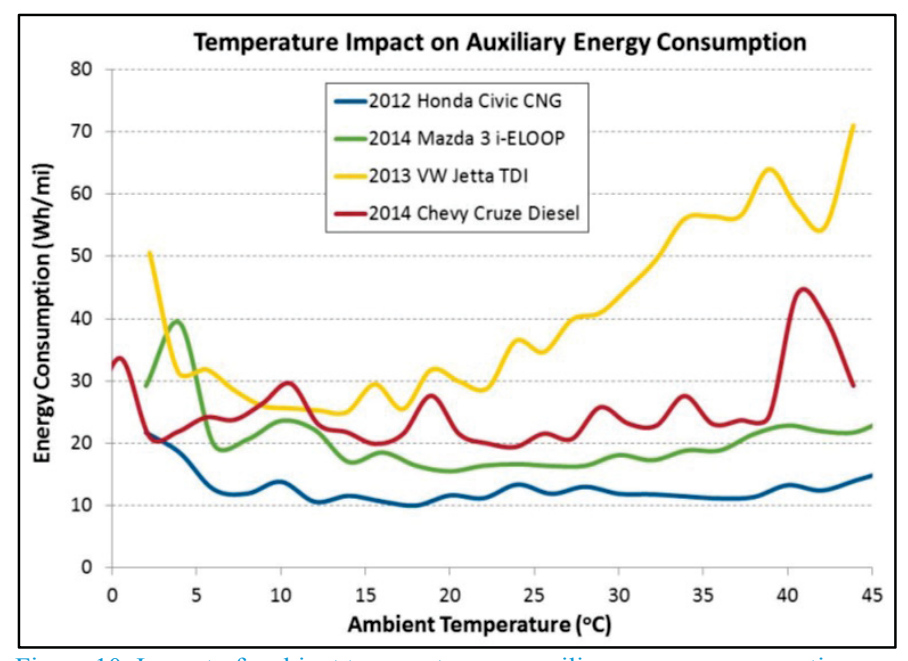

Figure 10. Impact of ambient temperature on auxiliary energy consumption

The average on-road auxiliary load energy consumption was determined for each vehicle model over the one-year data collection period. The results are shown in Table 5.

Table 5. Fleet average on-road auxiliary load energy consumption per vehicle model

\begin{tabular}{|l|c|}
\hline \multicolumn{1}{|c|}{ Vehicle Model } & $\begin{array}{c}\text { Average On-road Auxiliary Load } \\
\text { Energy Consumption (Wh/mi) }\end{array}$ \\
\hline 2012 Honda Civic CNG & 14.1 \\
\hline 2014 Mazda 3 i-ELOOP & 22.1 \\
\hline 2013 VW Jetta TDI & 39.6 \\
\hline 2014 Chevy Cruze Diesel & 26.2 \\
\hline
\end{tabular}

The on-road data collection provided detailed data and results that showed the wide variability in auxiliary load across vehicle models as well as the impact of many factors, especially ambient temperature.

\section{Impact of Auxiliary Load on Fuel Economy}

From literature review, it is know that typical alternator efficiency is $55 \%$ [6], typical maximum engine efficiency is up to $40 \%$ [6], and typically accessory drive belt efficiency is $98 \%$ [6]. This results in an approximate power conversion from fuel energy to electrical energy efficiency of $21 \%$ [6]. The fuel economy impact from the auxiliary load energy consumption can therefore be estimated from the measured on-road auxiliary load energy consumption and measured on-road fuel consumption.

Given the lower heating value for diesel is $36.0 \mathrm{kWh} / \mathrm{gal}$ [7] and gasoline (as well as CNG gasoline gallon equivalence) is 31.8 $\mathrm{kWh} / \mathrm{gal}$ [7], the auxiliary load energy consumption (Wh/mi) can be converted into gallons per mile. These results can be used to determine the auxiliary load percent of energy consumption from the total vehicle energy consumption. This was accomplished by using the average auxiliary load energy consumption as shown in Table 5. Table 6 shows the measured average on-road fleet fuel economy and fuel consumption of the four vehicle models [8-11] that were determined during the same on-road testing of the AVTE program. Table 6 also includes the auxiliary load energy consumption, and the percent contribution of auxiliary load on total on-road fuel consumption. The percent of total on-road fuel consumption that is consumed by the vehicle auxiliary loads varies from $7.5 \%$ to $18.1 \%$ as shown in table 6 . Since the auxiliary load consumes a significant amount of fuel during real world on-road driving, this reinforces the importance of the potential energy saving improvements that could be made by improving alternator efficiency or reducing auxiliary loads.

Table 6. Auxiliary Load impact on Vehicle Fuel Economy

\begin{tabular}{|c|c|c|c|c|}
\hline $\begin{array}{c}\text { Vehicle } \\
\text { Model }\end{array}$ & $\begin{array}{c}\text { Vehicle } \\
\text { On-road } \\
\text { (MPG) }\end{array}$ & $\begin{array}{c}\text { Vehicle } \\
\text { On-road } \\
\text { (Gal/mi) }\end{array}$ & $\begin{array}{c}\text { Aux. } \\
\text { Load } \\
\text { (Gal/mi) }\end{array}$ & $\begin{array}{c}\text { Aux Load \% } \\
\text { of Total Fuel } \\
\text { Consumption }\end{array}$ \\
\hline $\begin{array}{c}\text { 2012 Honda } \\
\text { Civic CNG }\end{array}$ & $36.3[8]$ & .0275 & .00196 & $7.5 \%$ \\
\hline $\begin{array}{c}2014 \text { Mazda } 3 \\
\text { i-ELOOP }\end{array}$ & $31.7[9]$ & .0315 & .00307 & $10.2 \%$ \\
\hline $\begin{array}{c}\text { 2013 VW } \\
\text { Jetta TDI }\end{array}$ & $35.5[10]$ & .0282 & .00484 & $18.1 \%$ \\
\hline $\begin{array}{c}\text { 2014 Chevy } \\
\text { Cruze Diesel }\end{array}$ & $35.6[11]$ & .0281 & .00320 & $12.0 \%$ \\
\hline
\end{tabular}

\section{Comparison of Auxiliary Load Results: On-road Operation and Chassis Dynamometer}

Dynamometer testing was conducted on the various vehicle models to determine the auxiliary load power and energy consumption during standard drive cycles. These results are compared to the results from the on-road driving data collection and analysis. Additionally the dynamometer testing was conducted at three ambient temperatures which enables the analysis of temperature impact on auxiliary load over standard drive cycles as well as comparison to the impact of ambient temperature on auxiliary load during on-road operation.

During dynamometer testing the driver controlled accessories are used in accordance to standardized test procedures. For example when testing at $23{ }^{\circ} \mathrm{C}$ ambient temperature, all accessories are placed in the off position including radio, lights, and HVAC controls. For testing at ambient temperatures of $-7{ }^{\circ} \mathrm{C}$ and $35{ }^{\circ} \mathrm{C}$, the HVAC is placed in the automatic setting at $22{ }^{\circ} \mathrm{C}$. In contrast, on-road accessory operation is chosen by the driver and can vary widely due to personal preference.

For comparison between on-road results and dynamometer results, the on-road driving route type percentage was determined for each vehicle model as percent city driving and percent highway driving. This was determined using the SAE J2841 definition based on vehicle speed of $42 \mathrm{mph}$ to distinguish between city and highway operation. Table 7 shows the percent on-road route type for comparison to dynamometer test results from standard drive cycles.

Table 7. On-road driving characteristics: city vs. highway driving route

\begin{tabular}{|l|c|c|}
\hline \multicolumn{1}{|c|}{ Vehicle Model } & City & Highway \\
\hline 2014 Mazda 3 i-ELOOP [12] & $47.0 \%$ & $53.0 \%$ \\
\hline 2013 VW Jetta TDI [13] & $91.3 \%$ & $8.7 \%$ \\
\hline 2014 Chevy Cruze Diesel [14] & $55.8 \%$ & $44.2 \%$ \\
\hline
\end{tabular}

The dynamometer results from all of the vehicle models show the expected trend of the minimum auxiliary load occurring at moderate temperature $\left(23{ }^{\circ} \mathrm{C}\right)$ and higher auxiliary loads at colder and hotter ambient temperatures.

Figure 11 shows the comparison of the dynamometer test results and the on-road driving results for the 2013 VW Jetta TDI. It is observed that the on-road results are within the range of the dynamometer 
drive cycle results at $35{ }^{\circ} \mathrm{C}$ and $-7{ }^{\circ} \mathrm{C}$. It is likely that the on-road drivers chose to operate the HVAC controls to create a comfortable driving environment which is similar to the HVAC settings during dynamometer testing at $35{ }^{\circ} \mathrm{C}$ and $-7{ }^{\circ} \mathrm{C}$. In contrast the on-road average auxiliary load is higher than dynamometer results at $23{ }^{\circ} \mathrm{C}$ again likely due to the driver preference to use accessories and HVAC to create comfortable driving conditions.

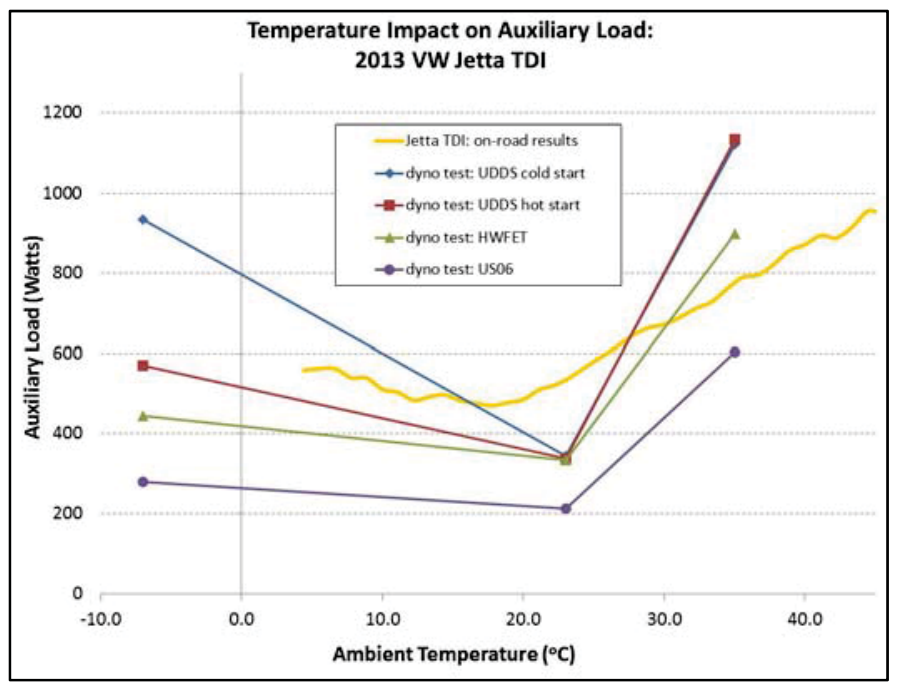

Figure 11. Dynamometer and On-road Comparison of Temperature Impact on the 2013 VW Jetta TDI

Figure 12 shows the comparison of the dynamometer test result and the on-road operation results for the 2014 Chevy Cruze Diesel. The on-road results are comprised of an approximately even mix of city and highway driving. The on-road results show reasonable correlation to the dynamometer results for the $23^{\circ} \mathrm{C}$ and $-7^{\circ} \mathrm{C}$ testing for the UDDS hot start and HWFET drive cycles but diverge significantly at $35^{\circ} \mathrm{C}$. The on-road results appear to show reasonable correlation to the $\mathrm{US} 06$ cycle at $35^{\circ} \mathrm{C}$.

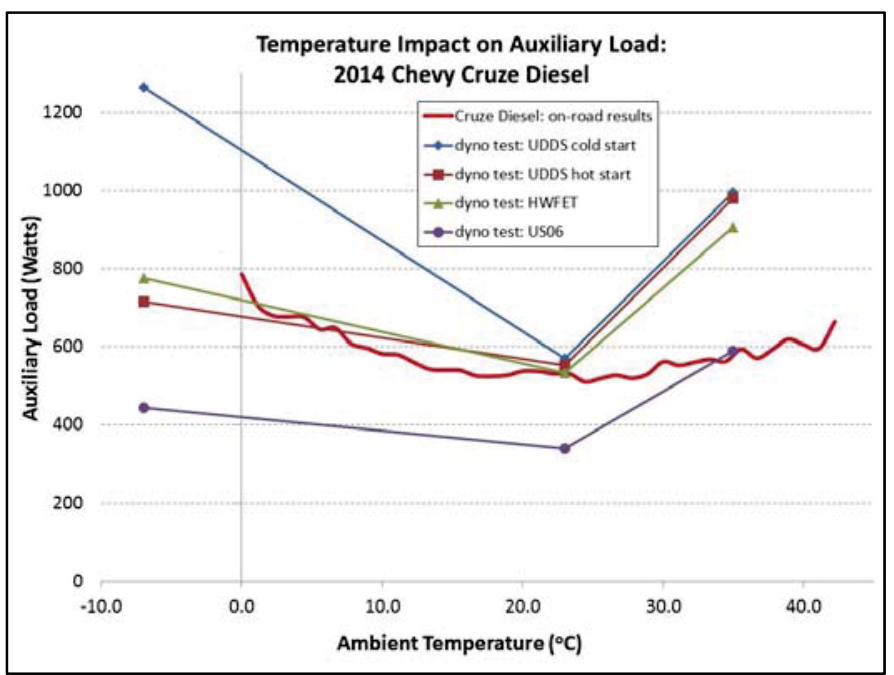

Figure 12. Dynamometer and On-road Comparison of Temperature Impact on the 2014 Chevy Cruze Diesel

Figure 13 shows the comparison of the dynamometer test result and the on-road operation results for the 2014 Mazda 3 i-ELOOP. The on-road results are clearly higher than the dynamometer results for all test cases except for the hot start UDDS at $35^{\circ} \mathrm{C}$. This could be a result of the variability of the actual on-road operation of accessories due to driver preference.

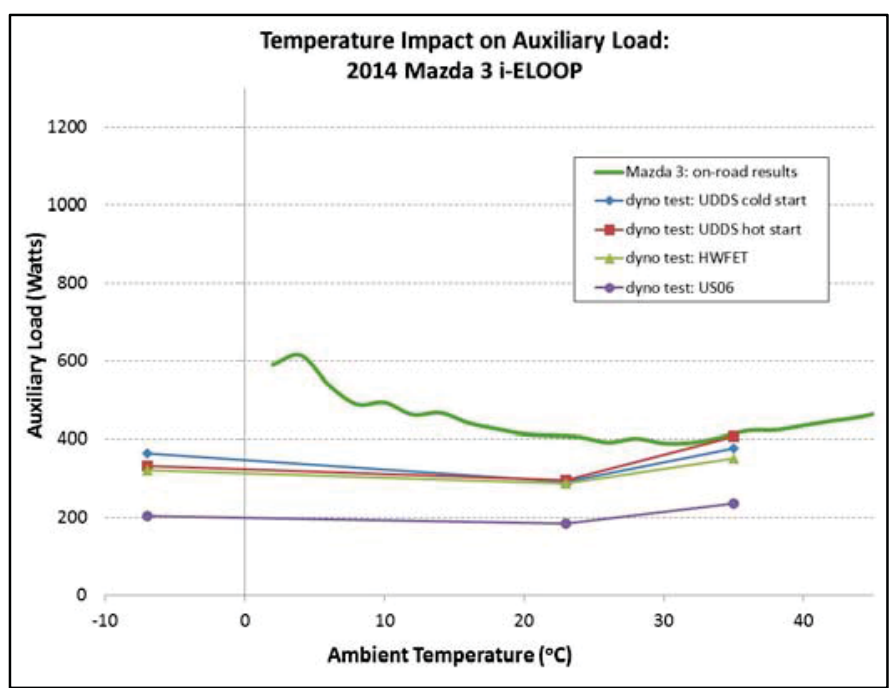

Figure 13. Dynamometer and On-road Comparison of Temperature Impact on the 2014 Mazda 3 i-ELOOP

The correlation between on-road results and dynamometer results shows the value from both data sources. One is a highly accurate and repeatable industry standard, where the other is the actual operation during real world driving with variability ranging from ambient conditions to driver's choice of accessory operation. Together the correlation provides a high level of confidence on the data quality and robustness.

\section{Summary}

Vehicle auxiliary load data collection, analysis, and characterization were conducted on sixteen non-electrified vehicles as part of the U.S. Department of Energy's Advanced Vehicle Testing Activity (AVTA). The information gathered in the study serves as a baseline to quantify future improvements in auxiliary load reduction technology. This study directly supports automotive manufacturers in regards to potential "off-cycle" fuel economy credits that are part of the U.S. CAFE regulations, in which credit is provided for advanced technologies that reduce the energy consumption from vehicle auxiliary loads.

Data was collected during the on-road operation of the sixteen vehicles over a one-year timeframe, as well as during dynamometer testing over standard drive cycles. Both testing environments included a wide range of ambient temperatures. The auxiliary loads during the on-road operation of 126,000 miles of the vehicles (four Volkswagen Jetta TDI, four Honda Civic CNG, four Mazda 3 iELOOP, and four Chevrolet Cruze Diesel vehicles) were analyzed. Also, the analysis details the impacts of various real-world driving and ambient conditions on auxiliary loads.

Chassis dynamometer testing was conducted on the same four vehicle models noted above, over several standard drive cycles (UDDS, HWFET, and US06) at three separate temperatures of $-7{ }^{\circ} \mathrm{C}, 23{ }^{\circ} \mathrm{C}$, as well as $35^{\circ} \mathrm{C}$ with $850 \mathrm{~W} / \mathrm{m}^{2}$ of solar emulation. Instrumentation was installed on each vehicle prior to dynamometer evaluation in order to capture $12 \mathrm{~V}$ power flow and energy consumption by the vehicle accessories. This was used to correlate and cross reference to the on-road data collection across the varying ambient conditions and temperatures.

The observed on-road auxiliary load varied from $135 \mathrm{~W}$ to over 1200 $\mathrm{W}$ across a wide range of ambient conditions and utilization patterns. The annual average auxiliary load varied across vehicle models from 
$310 \mathrm{~W}$ to $640 \mathrm{~W}$. Ambient temperature was the most predominant factor to impact auxiliary load since $\mathrm{A} / \mathrm{C}$ operation is prevalent at high ambient temperature and cabin heating is prevalent at cold ambient temperatures. Additionally, the impact of auxiliary load on the overall on-road vehicle fuel consumption was determined to be on average between $7.5 \%$ and $18 \%$. This shows the auxiliary load consumes a significant amount of energy during real world on-road driving as well as reinforces the importance of the potential energy saving improvements that could be made by improving alternator efficiency or reducing auxiliary loads.

\section{References}

[1] AVTA website: http://avt.inel.gov

[2] C. Waldman, S. Gurusubramanian, L. Fiorentini, \& M. Canova (2015). "A model-based supervisory energy management strategy for a $12 \mathrm{~V}$ vehicle electrical system", Control Engineering Practice, 44, pp. 20-30.

[3] C. Silva, M. Ross, \& T. Farias (2009). "Analysis and simulation of low-cost strategies to reduce fuel consumption and emissions in conventional gasoline light-duty vehicles", Energy Conversion and Management, 50(2), pp. 215-222.

[4] F. Chiara \& M. Canova (2013). "A review of energy consumption, management, and recover in automotive systems, with considerations of future trends", Proceedings of the Institution of Mechanical Engineers, Part D: Journal of Automobile Engineering, July 11, 2013.

[5] M. Lyu, B. Doo, \& Y. Ku (2007). "A study of vehicle fuel economy improvement potential by optimization of the cooling and ancillary systems of a heavy-duty engine", SAE Technical Paper 2007-01-1772.

[6] Bradfield, M. "Improving alternator Efficiency Measurably Reduces Fuel Costs", http://www.delcoremy.com/documents/ high-efficiency-white-paper.aspx Delco Remy Inc. 2008.

[7] GREET Model, https://greet.es.anl.gov/

[8] http://avt.inel.gov/pdf/ice/ar2012HondaCivicCNGICE.pdf

[9] http://avt.inel.gov/pdf/ice/ar2014MazdaMazda3GrandTouringIC E.pdf

[10] http://avt.inel.gov/pdf/ice/ar2013VolkswagenJettaTDIICE.pdf

[11] http://avt.inel.gov/pdf/ice/ar2014ChevyCruzeDieselICE.pdf

[12] http://avt.inel.gov/pdf/ice/auxloadMazda3ProjectToDateAug201 5.pdf

[13] http://avt.inel.gov/pdf/ice/auxloadJettaTDIProjectToDateAug20 15.pdf

[14] http://avt.inel.gov/pdf/ice/auxloadCruzeDieselProjectToDateAu g2015.pdf 